\title{
Dynamic Analysis of Half Car Model with MR Damper as Semi-Active Suspension Element
}

\author{
K. Hemanth, Hemantha Kumar and K. V. Gangadharan \\ National Institute of Technology Karnataka, Surathkal, Mangalore-575025, India.
}

(Received 16 August 2015; accepted 17 November 2016)

This paper presents the dynamic analysis of a half-car model with a magnetorheological (MR) damper subjected to random excitation. Experimental studies have been conducted to predict the behavior of the prototype twin-tube MR damper. The mathematical model of the prototype MR damper has been proposed by using the Bouc-Wen model. The half-car model with the MR damper has been used to predict the ride comfort and road holding performance. Comparative studies between the half-car model with the passive and semi-active suspension system with a proportional-integral-derivative (PID) control shows that the MR damper suspension system offers a good performance.

\section{INTRODUCTION}

The vehicle suspension system is used to mitigate vibrations which are transmitted from the road surface to the vehicle body. A good ride comfort requires a soft suspension, whereas a hard suspension is required for carrying heavy loads. A good handling of vehicles requires a suspension system which makes for better trade-offs between the above stated two criteria. In order to fulfill these conflicting requirements, a fully active or semi-active suspension system is preferred over a conventional passive suspension system. Active and semi-active suspensions are attracting more attention in improvement of both ride comfort and road holding. In particular, semi-active suspension offers a desirable performance enhanced by an active suspension without requiring high power consumption and expensive hardware.

Magneto-rheological (MR) dampers are semi-active devices that use MR fluids to provide controllable damping force. A typical MR fluid consists of 20-40 percent by volume of relatively pure (3-10 micron diameter size) magnetizable particles suspended in a carrier liquid such as mineral oil, synthetic oil, water or glycol. When the MR fluid is exposed to a magnetic field, particles in the fluid form chain-like structures in the direction of the applied magnetic field, and the fluid becomes like a semisolid material in a few milliseconds, by which it creates a resistance against the fluid flow. The yield stress of the fluid can be controlled very accurately by varying the magnetic field lintensity. Ashfak et al., ${ }^{1}$ studied the design, fabrication and performance evaluation of the MR damper and MR damper's applications in the field of vibration. Wen, ${ }^{2}$ proposed a mathematical model called the Bouc-Wen, which characterizes the MR damper behavior. Spencer et al., ${ }^{3}$ reviewed several idealized mechanical models for controllable fluid dampers. Kwok et al., ${ }^{4}$ and Giuclea et al., ${ }^{5}$ conducted experiment of the MR damper and the Bouc-Wen model has been considered to characterize the MR damper. The parameters of the Bouc-Wen model were evaluated by using a genetic algorithm and the proposed model was validated with experimental results. Cesmeci and Engin, ${ }^{6}$ have carried out experimental and theoretical studies to predict dynamic behavior of the MR damper, and the Bhingam plastic model is considered for theoretical study. Shivaram and Gangadharan, ${ }^{7}$ designed a statistical model of the MR damper using the design of the experimental approach. Various factors such as magnetic field strength, volume frac- tion of the magnetic particle, shearing gap between piston and cylinder, and amplitude and frequency of vibrations were considered in their experimentation. Avinash et al., ${ }^{8}$ developed the twin-tube MR damper and conducted an experiment to analyze the damping characteristic of the MR damper under different conditions such as air damping, viscous damping and MR damping.

Dutta et al., ${ }^{9}$ evaluated the performance of the sky-hook control strategy in the modified Bouc- Wen model of a quarter car model equipped with the MR damper under random and sinusoidal excitation. Song et al., ${ }^{10}$ studied the non-parametric modelling approach to predict the behavior of the MR damper. They used a series of continuous and differentiable mathematical functions to represent the characteristics of the physical damper. Metered et al., ${ }^{11}$ and Wang et al., ${ }^{12}$ carried out experimentations to study the dynamic characteristics of an MR damper and used the feed-forward recurrent neural network method to predict the behavior of the MR damper. Prabakar et al., ${ }^{13}$ evaluated the control of stationary response of the quarter car model for random excitation with the MR damper, and the optimal parameters of the MR damper were found using multi-objective optimization technique. Butz et al., ${ }^{14}$ provided an overview of properties of electro and MR fluids and their applications. They also discussed various phenomenological models of electrorheological (ER) and MR devices. Gopala and Narayanan, ${ }^{15}$ reported dynamic responses using the twodegree freedom quarter car model with nonlinear passive elements traversing a rough road with the sky-hook control strategy. Abdolvahab et al., ${ }^{16}$ and Agharkakli et al., ${ }^{17}$ studied the passive and active suspension system by using the quarter car model. Chen, ${ }^{18}$ proposed a sky-hook surface sliding mode control method to semi-active vehicle suspension system for its ride comfort enhancement. Rao et al., ${ }^{19}$ evaluated the ride comfort of off-road vehicles by replacing the normal passive damper with a controllable, two-state, semi-active damper and compared it to the passive suspension system. Sireteanu and Stoia $^{20}$ optimized the system nonlinear damping characteristics of passive and semi-active suspension with respect to ride comfort criterion. The proposed model shows that semi-active suspension with dry friction can provide good comfort improvement in comparison to passive suspensions. Turnip et al., ${ }^{21}$ investigated the numerical aspect of sensitivity control of a MR damper. They modelled a MR damper by using a non- 
parametric approach with a sixth order polynomial.

Prabakar et al.,22 studied the optimal preview control of the half-car model with a MR damper under random road excitation, and the MR damper has been modelled using a modified Bouc-Wen model. Rossi and Lucente, ${ }^{23}$ used H-infinity control strategy to quarter car and half-car the semi-active suspension system in order to improve the ride comfort and road handling performance. Eltantawie, ${ }^{24}$ developed a decentralized neuro-fuzzy controller to improve the ride and stability of the half-car model with the MR damper. They have evaluated the performance of the half-car model under two different road conditions (road bump and random road undulations) as inputs. They have also compared the obtained results with the passive suspension system. Karkoub et al., ${ }^{25}$ conducted an analytical study to evaluate the effectiveness of the MR damper in reduction of vibration by using the half-car model with the optimal control strategy. Kasprzyk and Krauze ${ }^{26}$ evaluated the performance of the semi-active half-car model with sky-hook and LMS control algorithms and compared the results between them. Hrovat, ${ }^{27}$ compared the performances of active and passive suspension systems on quarter, half and full car models using linear quadratic optimal control. Talib et al., ${ }^{28}$ evaluated the performance of the half-car active suspension system with self-tuning PID controller under different road conditions.

Significant research work has been carried out on ride comfort and road holding performance of the vehicle by using the quarter car vehicle model (Vertical dynamics), but only few researchers have been reported on the dynamic analysis of the half-car vehicle model (vertical and lateral/longitudinal dynamics). In the present work, the Bouc-Wen model was considered for verifying the dynamic behavior of the MR damper. NSGA-II technique is used to identify the parameter of the Bouc-Wen model. By using the estimated parameters of the Bouc-Wen model, the ride comfort and road holding capabilities of a semi-active suspension system using the half-car model with PID control is analyzed.

\section{METHODOLOGY}

The methodology (Fig. 1) demonstrates the experimentation of the designed twin-tube MR damper and analytical studies to predict the behavior of the MR damper. Dynamic analysis of the half-car model with passive suspension and semi-active suspension with the MR damper under random excitation has been carried out.

\section{MR FLUID PREPARATION}

MR fluid consists of $20-40$ percent by volume of relatively pure (3-10 micron diameter size) magnetizable particles, suspended in a carrier liquid such as mineral oil, synthetic oil, water or glycol. The MR fluids made from carbonyl iron particles exhibit maximum yield strengths of $50-100 \mathrm{kPa}$ for applied magnetic fields of $150-250 \mathrm{kA} / \mathrm{m}$. In the present study, 30 percent volume fraction of carbonyl iron particles with diameter of $6.23 \mu \mathrm{m}$ and density of $2.33 \mathrm{~g} / \mathrm{cm}^{3}$ is dispersed in silicon oil. The volume fraction of the suspended particle and carrier fluid were varied as per the requirements. The total volume of the MR fluid was $144 \mathrm{~cm}^{3}$, of which 30 percent volume fraction of carbonyl iron powder (around $100.6 \mathrm{~g}$ ) and 70 percent volume fraction of silicon oil (around $100.8 \mathrm{~cm}^{3}$ ) were taken in a container, and the mixture was stirred continuously for one day ( 24 hours) with the help of a mechanical stirrer in order to get

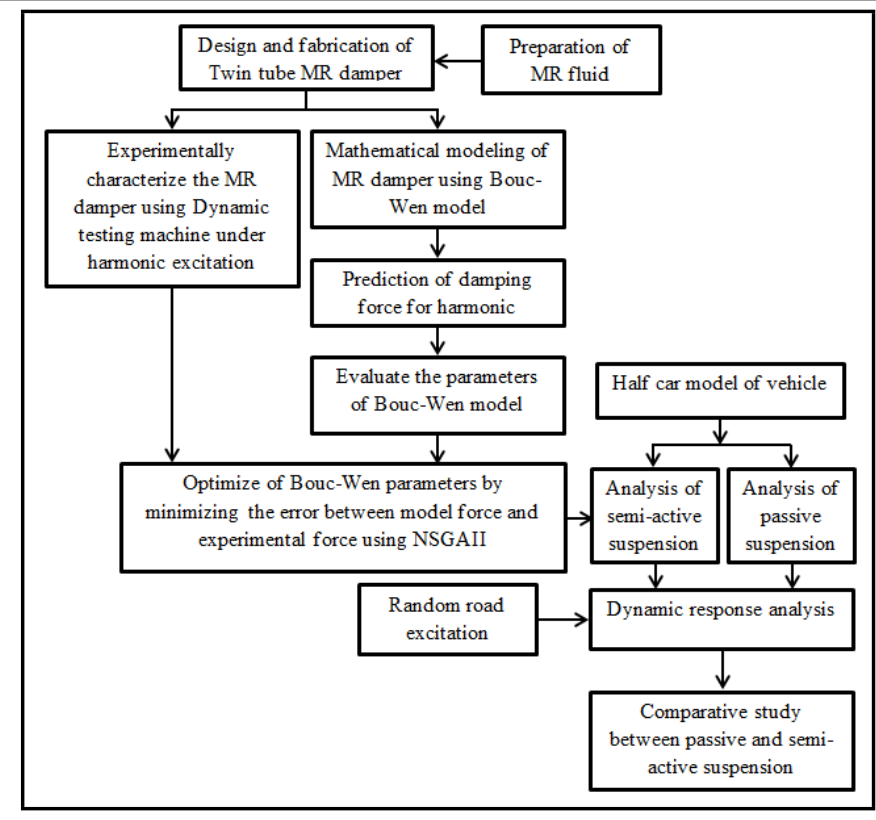

Figure 1. Methodology of the dynamic analysis of the MR damper.

a uniform distribution of carbonyl iron particles in the silicone oil. To reduce the sedimentation of particles, small amounts of grease were added as a stabilizer (Kolekar et al. ${ }^{29}$ ).

\section{DAMPER DESIGN SCHEME}

The design of the MR damper has been carried out similarly to the conventional hydraulic damper design with a necessary modification in the piston. In the MR damper, pistons having the electromagnetic coil capable of delivering the magnetic field in the fluid flow gap are provided around the piston. Pistons made up of magnetic steel material and piston rods with non-magnetic stainless steel having lower permeability is used to avoid flux leakage through the coil. The flow of the magnetic field depends upon the magnetic permeability of the material. According to the magnetic Ohm's law, the magnetic potential is given as follows:

$$
\begin{gathered}
N I=\Phi R_{m} ; \\
\phi=B A ;
\end{gathered}
$$

where $\phi$ is the magnetic flux, $R_{m}$ is total reluctance of the magnetic circuit, $I$ is the applied current, $N$ is the number of turns in a coil, $B$ is the magnetic flux density and $A$ is the cross-sectional area magnetic circuit.

The magnetic circuit of the MR damper is as shown in Fig. 2. The magnetic circuits mainly consist of magnetic core, yoke, cylinder and annular flow path. The total reluctance of the electromagnetic circuit is composed of magnetic core reluctance $\left(R_{\text {core }}\right)$, yoke reluctance $\left(R_{y}\right)$ cylinder reluctance $\left(R_{c}\right)$ and annular flow path reluctance $\left(R_{g}\right)$.

$$
\begin{gathered}
R_{m}=R_{\text {core }}+R_{y}+R_{c}+R_{g} \\
N=\frac{\phi\left(R_{\text {core }}+R_{y}+R_{c}+R_{g}\right)}{I} .
\end{gathered}
$$

In the present study based on past literature, $1.5 \mathrm{~mm}$ fluid flow gap has been considered between the piston and cylinder of the MR damper (Sternberg et al. ${ }^{30}$ ) for analysis. The designed dimension of the twin-tube MR damper is given in the Table 1. 


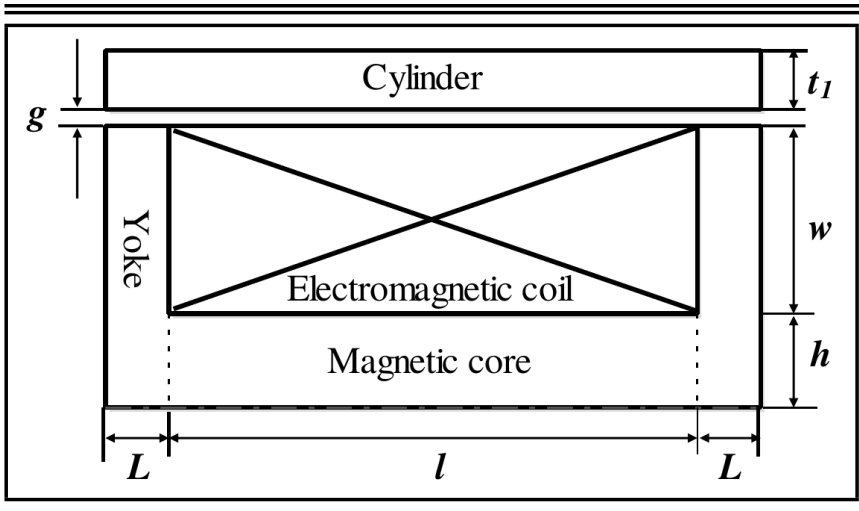

Figure 2. Electromagnetic circuit structure.

Table 1. Dimension of the twin-tube MR damper.

\begin{tabular}{||c|c|}
\hline Parameters & Dimensions (mm) \\
\hline Inner diameter of inner cylinder & 28 \\
\hline Thickness of inner cylinder $\left(t_{1}\right)$ & 5 \\
\hline Inner diameter of the outside cylinder & 46 \\
\hline Thickness of outer cylinder $\left(t_{2}\right)$ & 9 \\
\hline Distance between poles $(l)$ & 21 \\
\hline Flange length $(L)$ & 2 \\
\hline Radial distance from piston rod to coil width $(h)$ & 7.5 \\
\hline Coil width $(w)$ & 5 \\
\hline
\end{tabular}

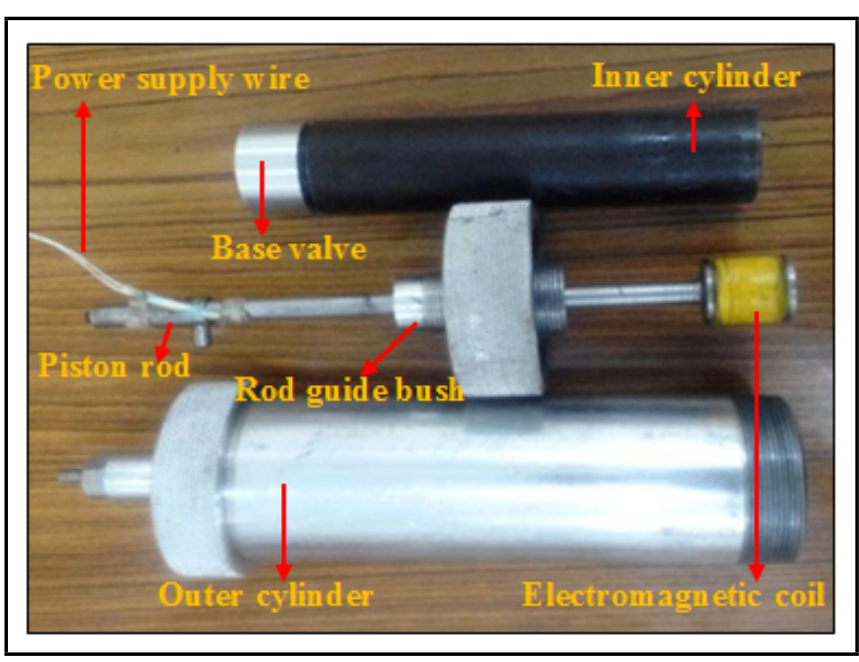

Figure 3. Component of MR damper.

\section{CHARACTERIZATION OF MR DAMPER}

The MR damper consists of a piston having an electromagnetic coil, inner cylinder and an outer cylinder. The MR damper is filled with MR fluid, which is controlled by a magnetic field, usually using an electromagnet. This allows the damping characteristics of the shock absorber to be continuously controlled by varying the current applied to the electromagnet. The components of the twin-tube MR damper is as shown in Fig. 3. The designed dimension of the twin-tube MR damper is given in Table 2. The electromagnetic circuit in the piston consist of a 1000 number of turns, and is subjected up to a maximum current of $1 \mathrm{~A}$ and $9 \mathrm{~V}$ electric potential.

To study the dynamic behavior of the designed MR damper, experimentation was carried out using a custom built damper testing machine as shown in Fig. 4. The main components of the damper testing machine are the shaker, linear variable differential transformer (LVDT), force transducer and a data acquisition system. The APS 420 ELECTRO-SEIS electrodynamics shaker was used for exciting the MR damper. The
Table 2. Dimension of the twin-tube MR damper.

\begin{tabular}{||l|c|}
\hline \multicolumn{1}{|c|}{ Parameters } & Dimensions $\mathbf{( m m )}$ \\
\hline Inner diameter of inner cylinder & 28 \\
\hline Thickness of inner cylinder $\left(t_{1}\right)$ & 5 \\
\hline Inner diameter of the outside cylinder & 46 \\
\hline Thickness of outer cylinder $\left(t_{2}\right)$ & 9 \\
\hline Distance between poles $(l)$ & 21 \\
\hline Pole length $(L)$ & 2 \\
\hline Radial distance from piston rod to coil width $(h)$ & 7.5 \\
\hline Coil width $(w)$ & 5 \\
\hline Clearance between piston and inner cylinder $(g)$ & 1.5 \\
\hline
\end{tabular}

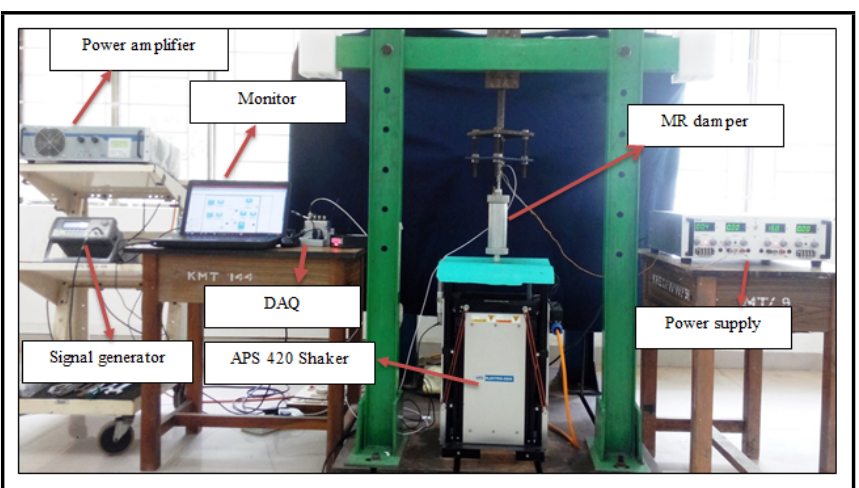

Figure 4. Experimental setup of the MR damper test setup.

shaker has a rated sine peak force $900 \mathrm{~N}$ with a frequency range of 1 to $200 \mathrm{~Hz}$. The rated peak to peak amplitude/displacement is $150 \mathrm{~mm}$. It can be operated manually or by PC based control mode and is compatible to PC based data actuation. The APS 145 power amplifier was used in the voltage mode in order to produce constant velocity.

The damper test was performed at $2 \mathrm{~Hz}$ frequency for different current values. The current varied from $0.1 \mathrm{~A}$ to $0.4 \mathrm{~A}$ (increment of $0.1 \mathrm{~A}$ ) with a sinusoidal signal of $+/-0.005 \mathrm{~m}$ amplitude. The current was monitored and supplied through a DC power supply (0-64 V/5 A Max.). The damping force experienced by the piston rod was sensed by a force transducer fitted at the top of the piston rod, and the displacement was measured through LVDT. The dynamic characteristic of the MR damper is analyzed in the result and discussion section.

\section{MR DAMPER MODELLING}

The characteristics of the MR damper was analytically verified by using the Bouc-Wen model is shown in Fig. 5. The Bouc-Wen model consists of a set of differential equations describing the hysteresis behavior of the MR damper. The damping force developed by the Bouc-Wen model (Sapinski and Filus ${ }^{31}$ ) is given in the Eq. (5).

$$
\begin{gathered}
F_{d}=c_{0} \dot{x}+k_{0} x+\alpha z ; \\
\dot{z}=\delta \dot{x}-\beta \dot{x}|z|^{n}-\gamma z|\dot{x}||z|^{n-1} ;
\end{gathered}
$$

where $F_{d}$ is the damper force, $\mathrm{k} 0$ is the stiffness and $c_{0}$ is the viscous coefficient respectively. $\alpha, \beta, \delta, \gamma$ and $n$ are the parameters that need to be adjusted in order to control the shape of the hysteretic curve. $Z$ is the hysteretic variable, and the parameters of the Bouc-Wen model are identified by using the non-dominated sorting genetic algorithm II (NSGA II) technique $\left(\mathrm{Deb}^{32}\right)$. In the MR damper, the MR fluid properties vary with the current $(I)$. Parameters $K_{0}$ and $C_{0}$ of the Bouc-Wen model is depending on the applied current to the damper, as current value changes the value of these two parameters also 


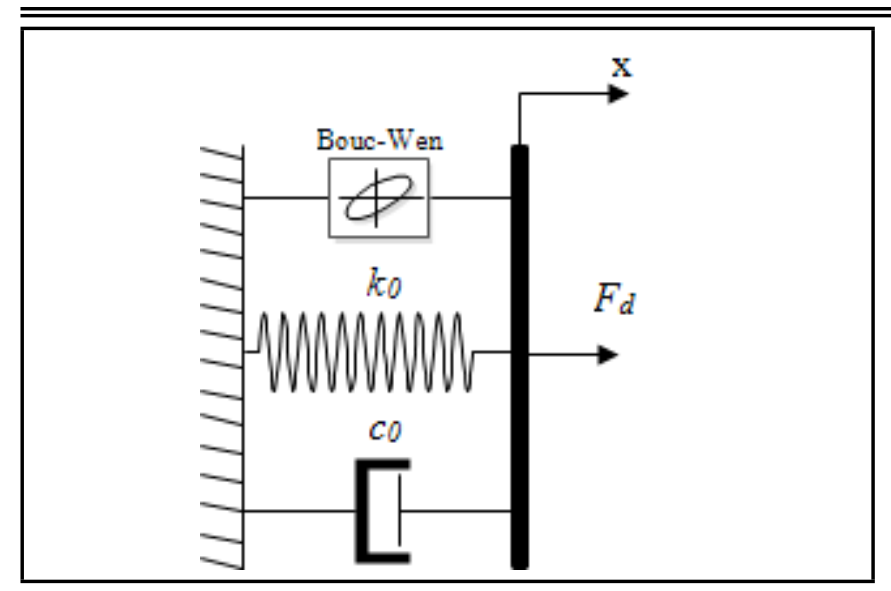

Figure 5. The Bouc-Wen model.

Table 3. The Optimized Bouc-Wen model parameters.

\begin{tabular}{|c|c|}
\hline Parameters & Optimized value \\
\hline$\alpha$ & 0.0106696 \\
\hline$\beta$ & 1577.0759 \\
\hline$\delta$ & 113.5895 \\
\hline$\gamma$ & 1926.2603 \\
\hline$n$ & 3 \\
\hline
\end{tabular}

changes. Hence, field dependent parameters and the applied current can be related by the first order polynomial function, and the coefficient of the functions (constant) are obtained by the curve fitting method is given in Eq. (7) and (8).

$$
\begin{gathered}
K_{0}=747 l+676.3 ; \\
C_{0}=526.4 l+79.73 .
\end{gathered}
$$

The parameters optimized for the Bouc-Wen model is obtained by minimizing the error between the Bouc-Wen model force and the experimental force as given in Eq. (9).

$$
J=\sum_{i=1}^{N}\left(F_{e i}-F_{p i}\right)^{2}
$$

where $F_{e}$ and $F_{p}$ are the experimental force and model force respectively. The optimized value of the Bouc-Wen model is given in Table 3.

\section{RANDOM ROAD PROFILE}

The performance of the quarter car suspension model is evaluated under random road disturbance. The power spectral density (PSD) function of random road distribution can be expressed as (Prabakar et al., ${ }^{13}$ Shinozuka and $\mathrm{Jan}^{33}$ ).

$$
S_{h}(\omega)=\frac{\sigma^{2} \alpha_{r} V}{\pi\left(\omega^{2}+\left(\alpha_{r} V\right)^{2}\right)} ;
$$

where $\sigma^{2}$ is the variance of the road profile, $\omega$ is the circular frequency, $\alpha_{r}$ is the road roughness coefficient and $V$ is the vehicle forward velocity. The PSD corresponding to the road excitation being the response of the first order liner filter to white noise excitation is given by:

$$
\dot{h}(t)+\alpha_{r} V h(t)=w(t)
$$

where $w(t)$ is the white noise process given by:

$$
w(t)=\sqrt{2} \sum_{k=1}^{N}\left[S_{0}\left(\omega_{k}\right) \Delta \omega\right]^{\frac{1}{2}} \cos \left(\omega_{k}+\phi_{k}\right) ;
$$

(a)

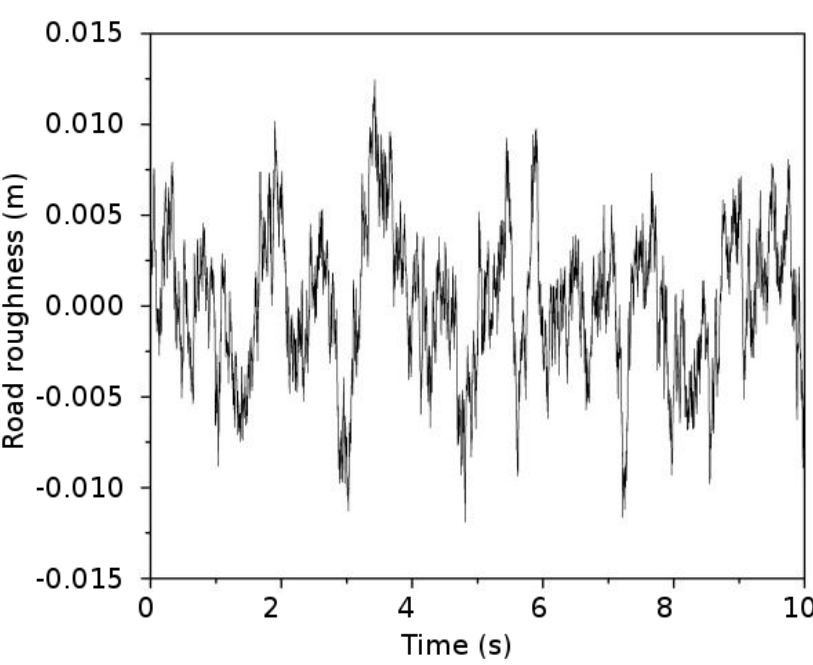

(b)

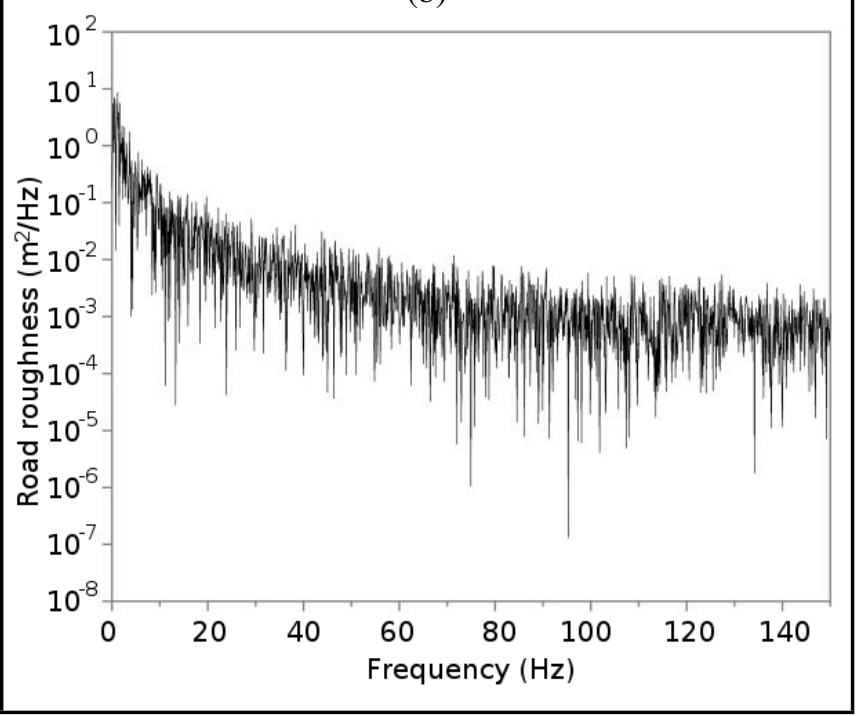

Figure 6. (a) Random road roughness profile in the time domain and (b) PSD of random road roughness profile.

where $S_{0}\left(\omega_{k}\right)$ is the single sided PSD of the road roughness at frequency $\omega_{k}$ with $\omega_{k}=\omega_{l}+\left(k-\frac{1}{2}\right)$ and $k=1,2,3 \ldots N$, $\Delta \omega=\left(\omega_{u}-\omega_{l}\right) / N, \omega_{u}$ and $\omega_{l}$ are the upper and lower cutoff frequency, $N$ is the number of the interval, $\dot{\omega}_{k}=\omega_{k}+\delta \omega$ in which $\delta \omega$ is small random frequency and $\phi_{k}$ is the independent random phase uniformly distributed between 0 to $2 \pi$. The random road profile is as shown in Fig. 6.

\section{HALF-CAR MODEL}

A half-car suspension model with four degree of freedom system (Fig. 7) is analyzed by considering the vertical displacement and pitch movement $(\phi)$ of the vehicle body. The nomenclature and detail of the half-car model (Patel et al. ${ }^{34}$ ) are given in Table 4.

The equation of motion of a half-car suspension system can be derived by applying Newton's second law of motion - see Eqs. (13) and (14) on the top of next page.

The above mentioned equation can be written in the form of state space variables as given by Eqs. (15)-(18) on the next page. 


$$
\begin{aligned}
& M_{s} \ddot{x}_{s}+K_{s f}\left(x_{s f}-x_{u f}\right)+K_{s r}\left(x_{s r}-x_{u r}\right)+F_{d f}+F_{d r}=0 \\
& I \ddot{\theta}+L_{1} K_{s f}\left(x_{s f}-x_{u f}\right)-L_{2} K_{s r}\left(x_{s r}-x_{u r}\right)+L_{1} F_{d f}-L_{2} F_{d r}=0 \\
& \left.\begin{array}{c}
M_{u f} \ddot{x}_{u f}+C_{t f}\left(\dot{x}_{u f}-\dot{h}_{f}\right)+K_{t f}\left(x_{u f}-h_{f}\right)-K_{s f}\left(x_{s f}-x_{u f}\right)-F_{d f}=0 \\
M_{u r} \ddot{x}_{u r}+C_{t r}\left(\dot{x}_{u r}-\dot{h}_{r}\right)+K_{t r}\left(x_{t r}-h_{r}\right)-K_{s r}\left(x_{s r}-x_{u r}\right)-F_{d r}=0
\end{array}\right\} ; \\
& \left.\begin{array}{l}
x_{s f}=x_{s}+L_{1} \theta \\
x_{s r}=x_{s}-L_{2} \theta
\end{array}\right\} \\
& \left.\begin{array}{l}
\dot{x}=A x+B u \\
y=C x+D u
\end{array}\right\} \\
& x=\left[\begin{array}{llllllll}
x_{s} & \theta & x_{u f} & x_{u r} & \dot{x}_{s} & \dot{\theta} & \dot{x}_{u f} & \dot{x}_{u r}
\end{array}\right]^{T} ; \quad u=\left[\begin{array}{llllll}
F_{d f} & F_{d r} & h_{f} & \dot{h}_{f} & h_{r} & \dot{h}_{r}
\end{array}\right]^{T} ; \\
& A=\left[\begin{array}{cc}
0 & 0 \\
0 & 0 \\
0 & 0 \\
0 & 0 \\
-\left(\frac{K_{s f}+K_{s r}}{M_{s}}\right) & \left(\frac{L_{2} K_{s r}-L_{1} K_{s f}}{M_{s}}\right) \\
\left(\frac{L_{2} K_{s r}-L_{1} K_{s f}}{I}\right) & -\left(\frac{L_{1}{ }^{2} K_{s f}+L_{2}{ }^{2} K_{s r}}{I}\right) \\
\frac{K_{s f}}{M_{u f}} & \frac{L_{1} K_{s f}}{M_{u f}} \\
\frac{K_{s r}}{M_{u r}} & \frac{-L_{2} K_{s r}}{M_{u r}}
\end{array}\right. \\
& 0 \\
& 0 \\
& 0 \\
& 0 \\
& \frac{K_{s f}}{M_{s}} \\
& \frac{L_{1} K_{s f}}{I} \\
& -\left(\frac{K_{t f}+K_{s f}}{M_{u f}}\right) \\
& \left.\begin{array}{llllcc}
0 & 0 & 0 & \frac{-C_{t f}}{M_{u f}} & 0 \\
0 & -\left(\frac{K_{s r}+K_{t r}}{M_{u r}}\right) & 0 & 0 & 0 & \frac{-C_{t r}}{M_{u r}}
\end{array}\right] \\
& B=\left[\begin{array}{cccccc}
0 & 0 & 0 & 0 & 0 & 0 \\
0 & 0 & 0 & 0 & 0 & 0 \\
0 & 0 & 0 & 0 & 0 & 0 \\
0 & 0 & 0 & 0 & 0 & 0 \\
\frac{-1}{M_{s}} & \frac{-1}{M_{s}} & 0 & 0 & 0 & 0 \\
\frac{-L_{1}}{I} & \frac{L_{2}}{I} & 0 & 0 & 0 & 0 \\
\frac{1}{M_{u f}} & 0 & \frac{K_{t f}}{M_{u f}} & \frac{C_{t f}}{M_{u f}} & 0 & 0 \\
0 & \frac{1}{M_{u r}} & 0 & 0 & \frac{K_{t r}}{M_{u r}} & \frac{C_{t r}}{M_{u r}}
\end{array}\right] \\
& \left.\begin{array}{c}
C=\left[\begin{array}{rrrrrrrr}
1 & 0 & 0 & 0 & 0 & 0 & 0 & 0 \\
0 & 1 & 0 & 0 & 0 & 0 & 0 & 0
\end{array}\right] \\
D=\left[\begin{array}{llllll}
0 & 0 & 0 & 0 & 0 & 0
\end{array}\right]
\end{array}\right\}
\end{aligned}
$$

Table 4. Nomenclature and details of the half-car model.

\begin{tabular}{|l|c|}
\hline \multicolumn{1}{|c|}{ Parameters } & Values \\
\hline Sprung mass $\left(M_{s}\right)$ & $1200 \mathrm{~kg}$ \\
\hline Body mass moment of inertia $(I)$ & $2100 \mathrm{~kg} \cdot \mathrm{m}^{2}$ \\
\hline Front unsprung mass $\left(M_{u f}\right)$ & $62.2 \mathrm{~kg}$ \\
\hline Rear unsprung mass $\left(M_{u r}\right)$ & $60 \mathrm{~kg}$ \\
\hline Front suspension stiffness $\left(K_{s f}\right)$ & $28000 \mathrm{~N} / \mathrm{m}$ \\
\hline Rear suspension stiffness $\left(K_{s r}\right)$ & $21000 \mathrm{~N} / \mathrm{m}$ \\
\hline Front suspension damping $\left(C_{s f}\right)$ for passive system & $2500 \mathrm{~N} \cdot \mathrm{s} / \mathrm{m}$ \\
\hline rear suspension damping $\left(C_{s r}\right)$ for passive system & $2000 \mathrm{~N} \cdot \mathrm{s} / \mathrm{m}$ \\
\hline Front and rear tyre stiffness $\left(K_{t f}\right.$ and $\left.K_{t r}\right)$ & $134000 \mathrm{~N} / \mathrm{m}$ \\
\hline Front and rear tyre damping $\left(C_{t f}\right.$ and $\left.C_{t r}\right)$ & $700 \mathrm{~N} \cdot \mathrm{s} / \mathrm{m}$ \\
\hline Location of center of gravity from front axle $\left(L_{1}\right)$ & $0.847 \mathrm{~m}$ \\
\hline Location of center of gravity from rear axle $\left(L_{2}\right)$ & $1.513 \mathrm{~m}$ \\
\hline
\end{tabular}

\subsection{Control strategy}

A proportional-integral-derivative (PID) controller is a closed loop feedback control system. The PID controller evaluates and minimizes the error value as a difference between a measured process variable and a desired set point (Gaur and Sheilza $^{35}$ ). The controller algorithm involves proportional (P), integral (I) and derivative (D) constants. The PID control strategy is given in Eq. (19).

$$
u(t)=K_{p} e(t)+K_{i} \int_{0}^{t} e(t) d t+K_{d} \frac{d e(t)}{d t}
$$

where, $u_{t}$ is the control signal, $K_{p}$ is the proportional coefficient, $K_{i}$ is the integral co-efficient, $K_{d}$ is the derivative co-efficient, $e(t)$ is the error signal $\left(e=u-u_{\text {ref }}\right), u$ is the

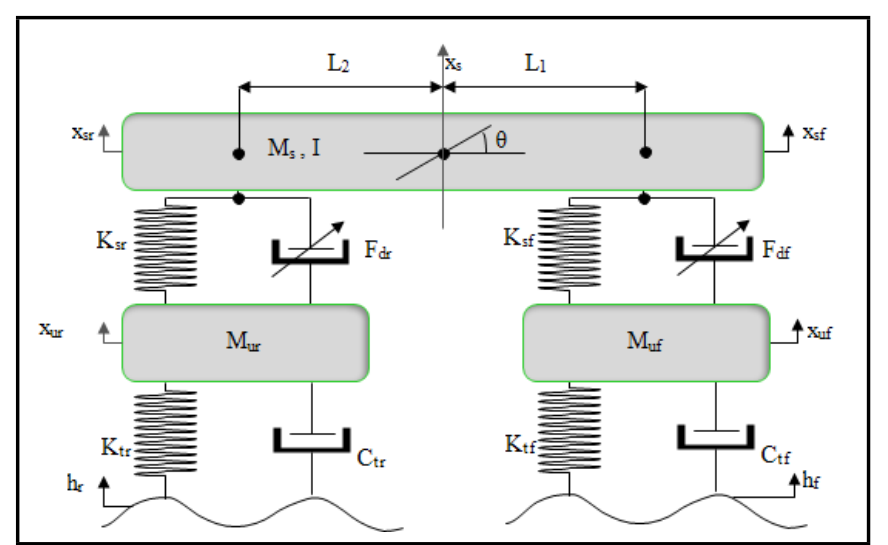

Figure 7. Half-car suspension with the MR damper.

Table 5. Optimal parameter of the PID controller.

\begin{tabular}{|c|c|c|c|}
\hline Parameters & $K_{p}$ & $K_{i}$ & $K_{d}$ \\
\hline Value & 2 & 0.5 & 10 \\
\hline
\end{tabular}

measured process variable and $u_{\text {ref }}$ is the reference value. The relative displacement between sprung and unsprung is given as an input to the PID controller. The optimal parameter of the PID controller is given in Table 5.

\section{RESULT AND DISCUSSION}

The fabricated MR damper was tested at a $2 \mathrm{~Hz}$ frequency for different current values under the sinusoidal excitation. The 


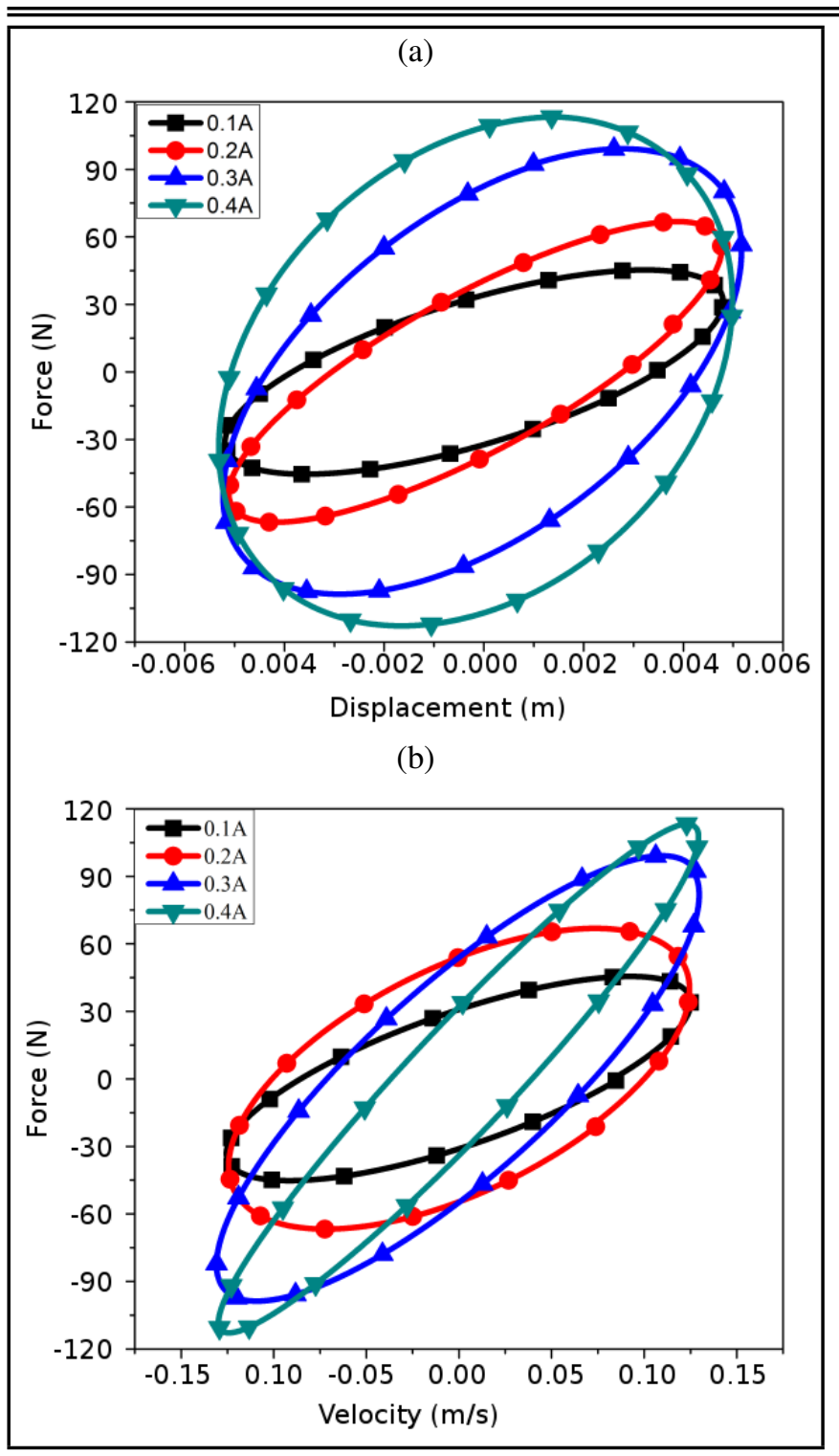

Figure 8. (a) Force $v / s$ displacement and (b) Force v/s velocity of the experimental result.

dynamic behaviour of an MR damper analysed by using force $v / s$ displacement and force $v / s$ velocity curve are shown in Fig. 8. From an observation at the lower input current, the damping force is less and it increased gradually with an increase in current. The slope of the curve increased with an increase in current, which indicates an increase in stiffness.

It is observed that as the current increased, the area enclosed under the force $v / s$ displacement curve also increased, which represents an increase of energy dissipation. Fig. 9 illustrates a comparison of the experimental and the proposed model damping force, a good agreement is observed between them.

The ride comfort and road holding performance of the passive and semi-active half-car suspension system has been evaluated under random excitation for different vehicle velocities. In the semi-active suspension system, the MR damper was modelled as the Bouc-Wen model, and the estimated parameter values of the Bouc-Wen model was used to carry out the simulation. The acceleration and its PSD response of the passive and semi-active half-car suspension system under random road distribution at constant speed of $35 \mathrm{~m} / \mathrm{s}$ are illustrated in Figs. 10 and 11. It is observed that, the vibration level of vehicle body is significantly reduced in the case of a semi-active

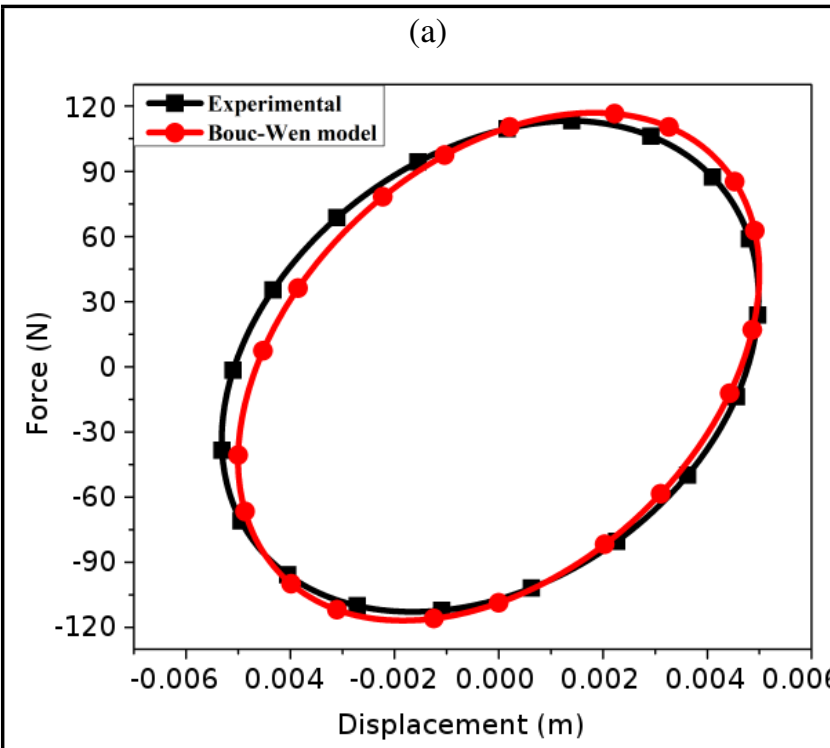

(b)

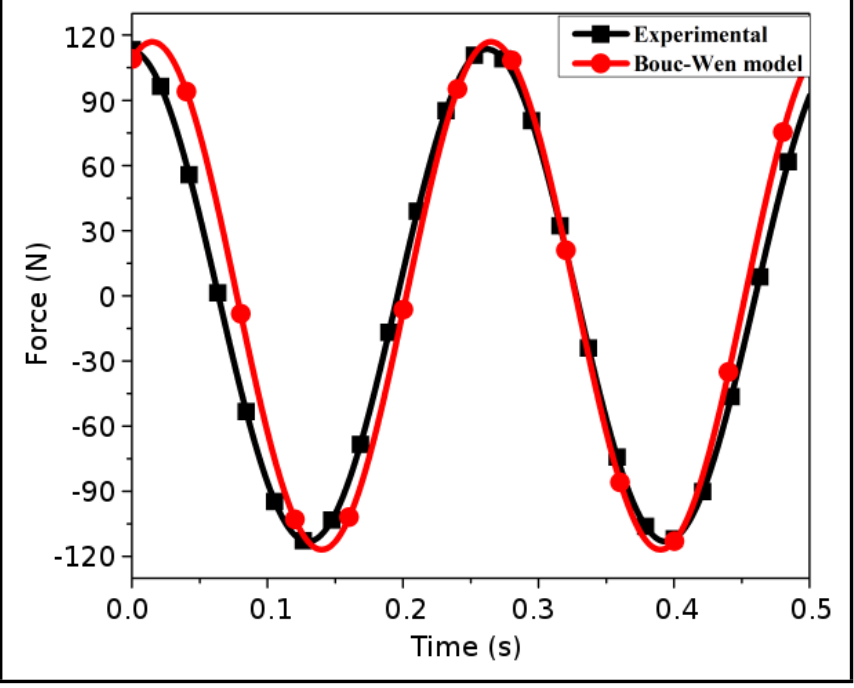

Figure 9. Comparison of the experimental and the predicted model force.

suspension system than a passive suspension system.

Figure 12(a) and (b) depicts the pitch rate of a passive and semi-active sprung mass. In this case, the semi-active suspension system also shows better performance.

Figures 13 and 14 depicts the root mean square (RMS) of the sprung mass acceleration, and the pitch angle acceleration response of the passive and semi-active suspension system for different vehicle velocities. In the semi-active suspension system, it can be observed that the increase in velocity results in significant reduction in the vertical acceleration of the sprung mass and pitch acceleration. This indicates that the semi-active suspension system provides better ride comfort for a vehicle.

Figure 15 illustrates the RMS road holding response of the front and rear wheel, which measures the relative displacement between the unsprung mass and the road displacement with respect to the different velocities. In this case also, road holding will be better with the semi-active suspension rather than the passive suspension for all velocities.

\section{CONCLUSION}

The MR damper has been designed for maximum load of $20 \mathrm{kN}$ force and the electromagnetic circuit in the piston con- 


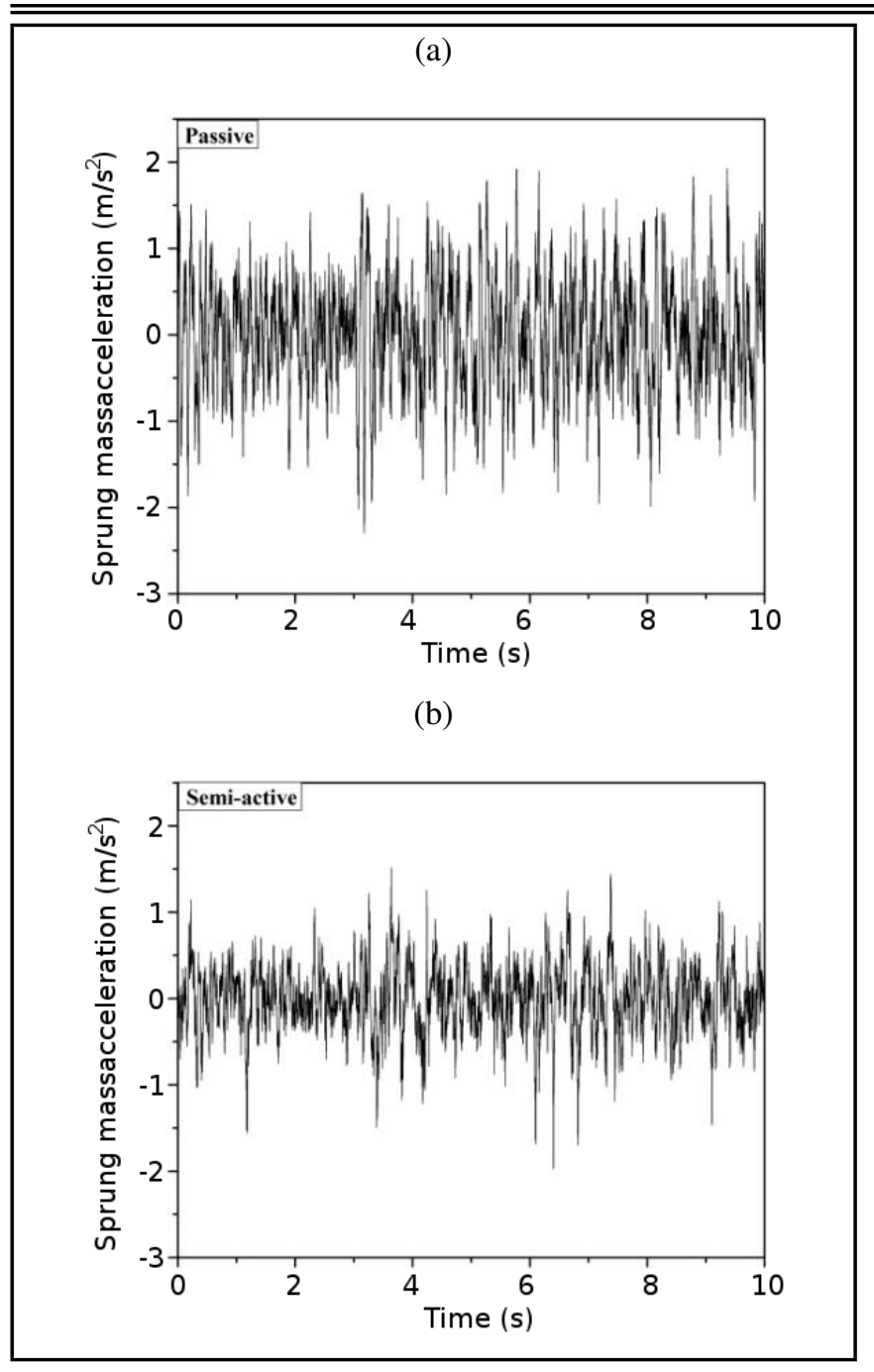

Figure 10. Response of the passive and semi-active sprung mass acceleration in the time domain.

sists of 1000 number of turns, and is subjected up to a maximum current of $1 \mathrm{~A}$ and $9 \mathrm{~V}$ electric potential. The experimental and analytical studies were conducted to predict the dynamic behavior of the MR damper. The designed twin-tube MR damper was tested under harmonic excitation. The result demonstrates that damping force increased with an increase in current, which leads to an increase in energy dissipation and stiffness. The dynamic force of an MR damper is analytically predicted by using the Bouc-Wen model. A good agreement has been observed between the proposed model and the experimental results. The passive and the MR damper based half-car suspension system is modeled and simulated under the random road profile with PID control. The MR damper based suspension system with the PID controller reduces around 33 percent of vibration amplitude at resonance frequency of the vehicle, and shows 40 percent improvement in road holding performance of the vehicle than with the passive suspension system.

\section{ACKNOWLEDGEMENTS}

The authors acknowledge the funding support from Department of Science and Technology (DST): No.SB/FTP/ETA0071/2013 and also acknowledge SOLVE Lab: The Virtual Lab @ NITK (www.solve.nitk.ac.in) and Centre for System Design (CSD): A Centre of excellence at NITK-Surathkal, for providing experimental facility.

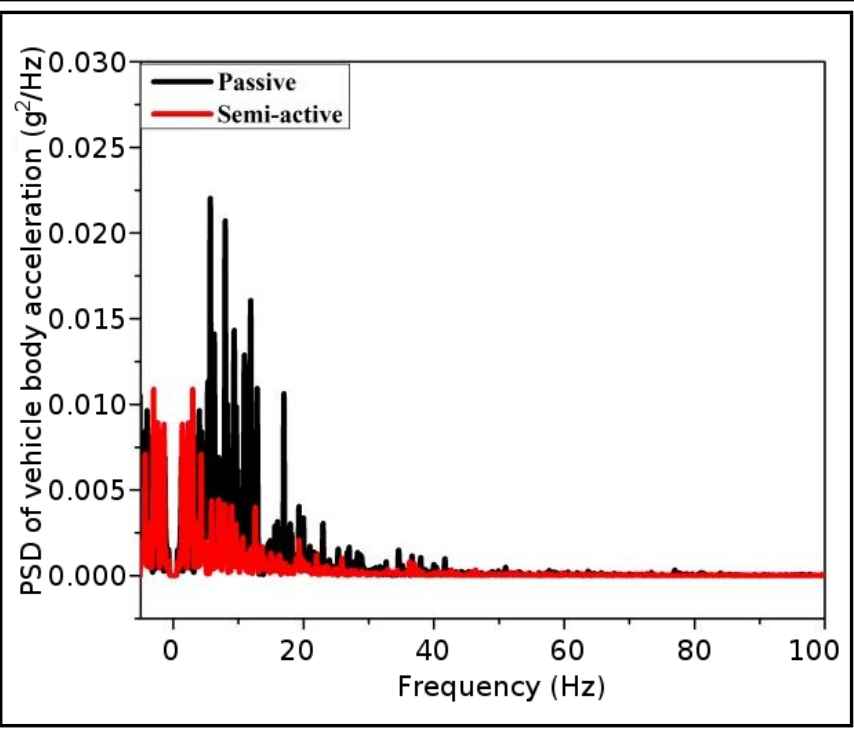

Figure 11. PSD of the passive and semi-active sprung mass acceleration.

\section{REFERENCES}

1 Ashfak, A., Saheed, A., Rasheed, K. K. and Jaleel, J. A., Design, Fabrication and Evaluation of MR Damper, Proceedings of World Academy of Science: Engineering and Technology. 53, (2009).

2 Wen, Y. K, Method of random vibration of hysteretic systems, Journal of Engineering Mechanics, 102 (2), 249-263, (1976).

3 Spencer, B. F., Dyke, S. J., Sain, M. K., and Carlson, J., Phenomenological model for magnetorheological dampers, Journal of engineering mechanics, 123(3), 230-238, (1997). https://dx.doi.org/10.1061/(ASCE)07339399(1997)123:3(230)

4 Kwok, N. M., Ha, Q. P., Nguyen, M. T., Li, J. and Samali, B., Bouc-Wen model parameter identification for a MR fluid damper using computationally efficient GA, ISA transactions, 46(2), 167-179, (2007). https://dx.doi.org/10.1016/j.isatra.2006.08.005

5 Giuclea, M., Sireteanu, T., Stancioiu, D., and Stammers, C. W., Modelling of magnetorheological damper dynamic behaviour by genetic algorithms based inverse method, Proceedings of Romanian Academy, 5(1), 1-10, (2004).

${ }^{6}$ Cesmeci, S., and Engin, T., Modelling and testing of a fieldcontrollable magnetorheological fluid damper, International Journal of Mechanical Sciences, 52(8), 1036-1046, (2010). https://dx.doi.org/10.1016/j.ijmecsci.2010.04.007

7 Shivaram, A. C. and Gangadharan, K. V., Statistical modelling of a magneto-rheological fluid damper using the design of experiments approach, Smart materials and structures, 16(4), 1310, (2007). https://dx.doi.org/10.1088/0964$1726 / 16 / 4 / 044$

8 Avinash, B., Sundar, S. S. and Gangadharan, K. V., Experimental Study of Damping Characteristics of Air, Silicon Oil, Magneto Rheological Fluid on Twin-Tube Damper, Procedia Materials Science, 5, 2258-2262, (2014). https://dx.doi.org/10.1016/j.mspro.2014.07.443 


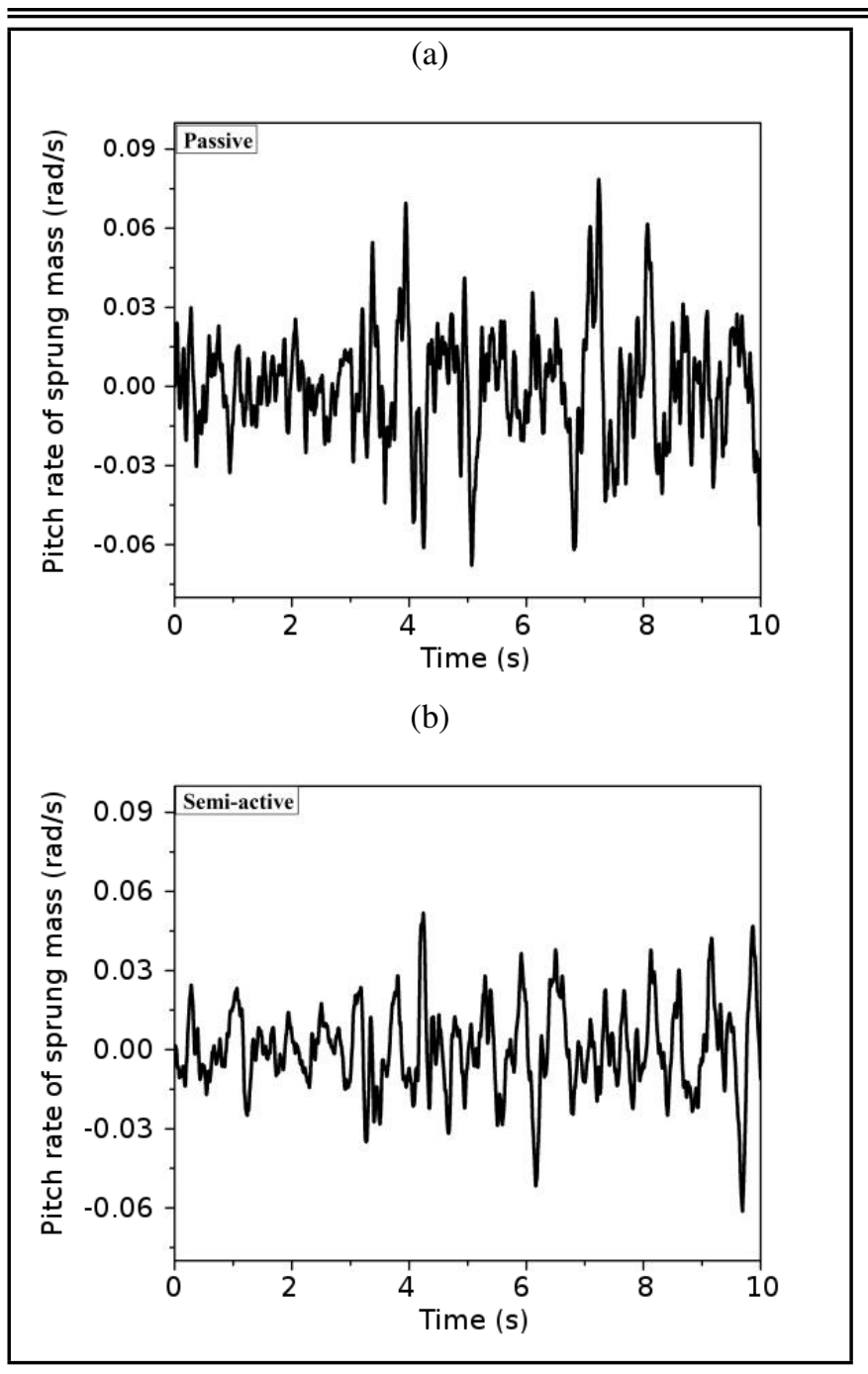

Figure 12. Pitch rate of the passive and semi-active sprung mass.

9 Dutta, S., Narahari, S. and Chakraborty, G., Semi-active vibration isolation of a quarter car model under random road excitations using magnetorheological damper, International and National Conference on Machines and Mechanisms, 999-1005, (2013).

10 Song xubin, Mehdi ahmadian and Steve, C., Southward, Modelling MR dampers with application of nonparametric approach, Journal of Intelligent Material Systems and Structures, 16.5, 421-432, (2005). https://dx.doi.org/10.1177/1045389X05051071

11 Metered, H., Bonello, P. and Oyadiji, S. O., The experimental identification of magnetorheological dampers and evaluation of their controllers, Mechanical Systems and Signal Processing, 24(4), 976-994, (2010). https://dx.doi.org/10.1016/j.ymssp.2009.09.005

12 Wang, D. H. and Liao, W. H., Modelling and control of magneto-rheological fluid dampers using neural networks, Smart Materials and Structures, 14(1), 111-126, (2005). https://dx.doi.org/10.1088/0964-1726/14/1/011

13 Prabakar, R. S., Sujatha, C. and Narayanan, S., Response of a quarter car model with optimal magnetorheological damper parameters, Journal of Sound and Vibration, 332(9), 2191-2206, (2013). https://dx.doi.org/10.1016/j.jsv.2012.08.021

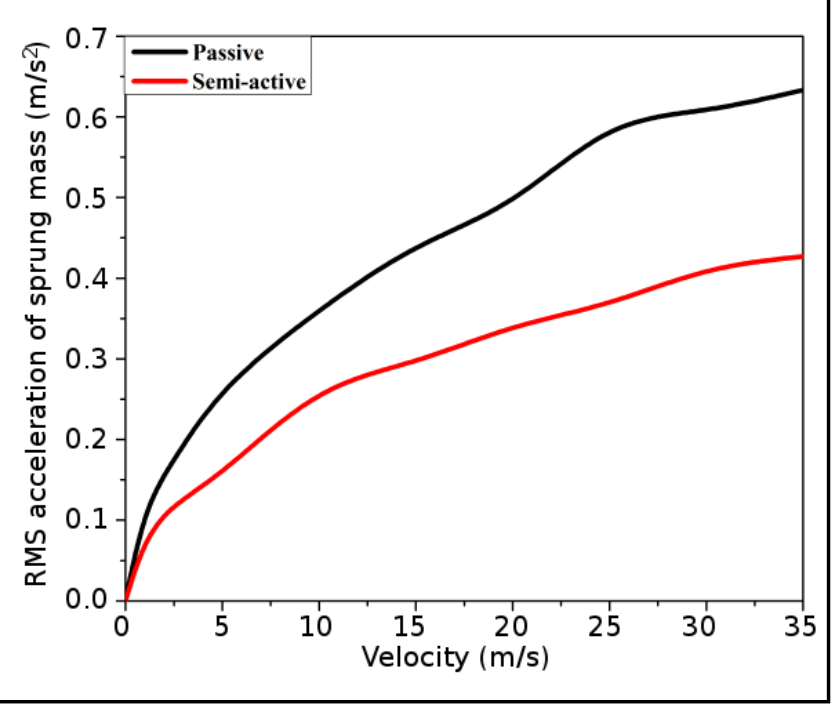

Figure 13. Vertical acceleration of sprung mass.

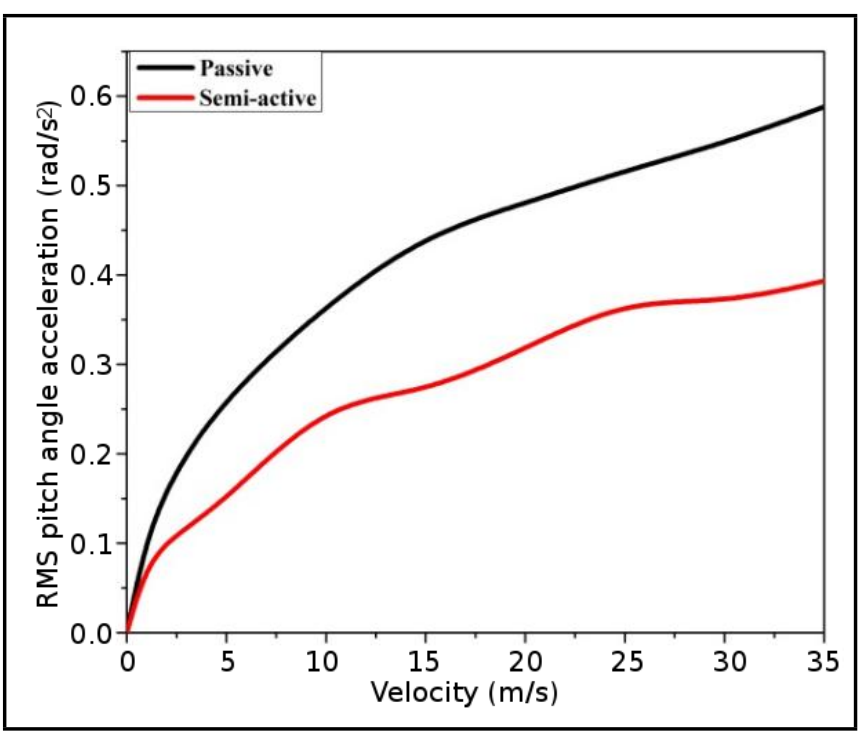

Figure 14. Angular acceleration of sprung mass.

14 Butz, T. and Von Stryk, O., Modelling and simulation of electro- and magnetorheological fluid dampers, ZAMM, 82(1), 3, (2002).

15 Gopala Rao, L.V.V. and S. Narayanan, Sky-hook control of nonlinear quarter car model traversing rough road matching performance of LQR control, Journal of Sound and Vibration, 323, 515-529, (2009). https://dx.doi.org/10.1016/j.jsv.2009.01.025

16 Abdolvahab, A., Chavan, U. S. and Phvithran, D. S., Simulation And Analysis Of Passive And Active Suspension System Using Quarter Car Model For Non Uniform Road Profile, International Journal of Engineering Research and Applications, 2(5), 900-906, (2012).

17 Agharkakli, A., Sabet, G. S. and Barouz, A., Simulation and analysis of passive and active suspension system using quarter car model for different road profile, International Journal of Engineering Trends and Technology, 3(5), 636644, (2012).

18 Chen, Y., Skyhook surface sliding mode control on semi-active vehicle suspension system for ride com- 


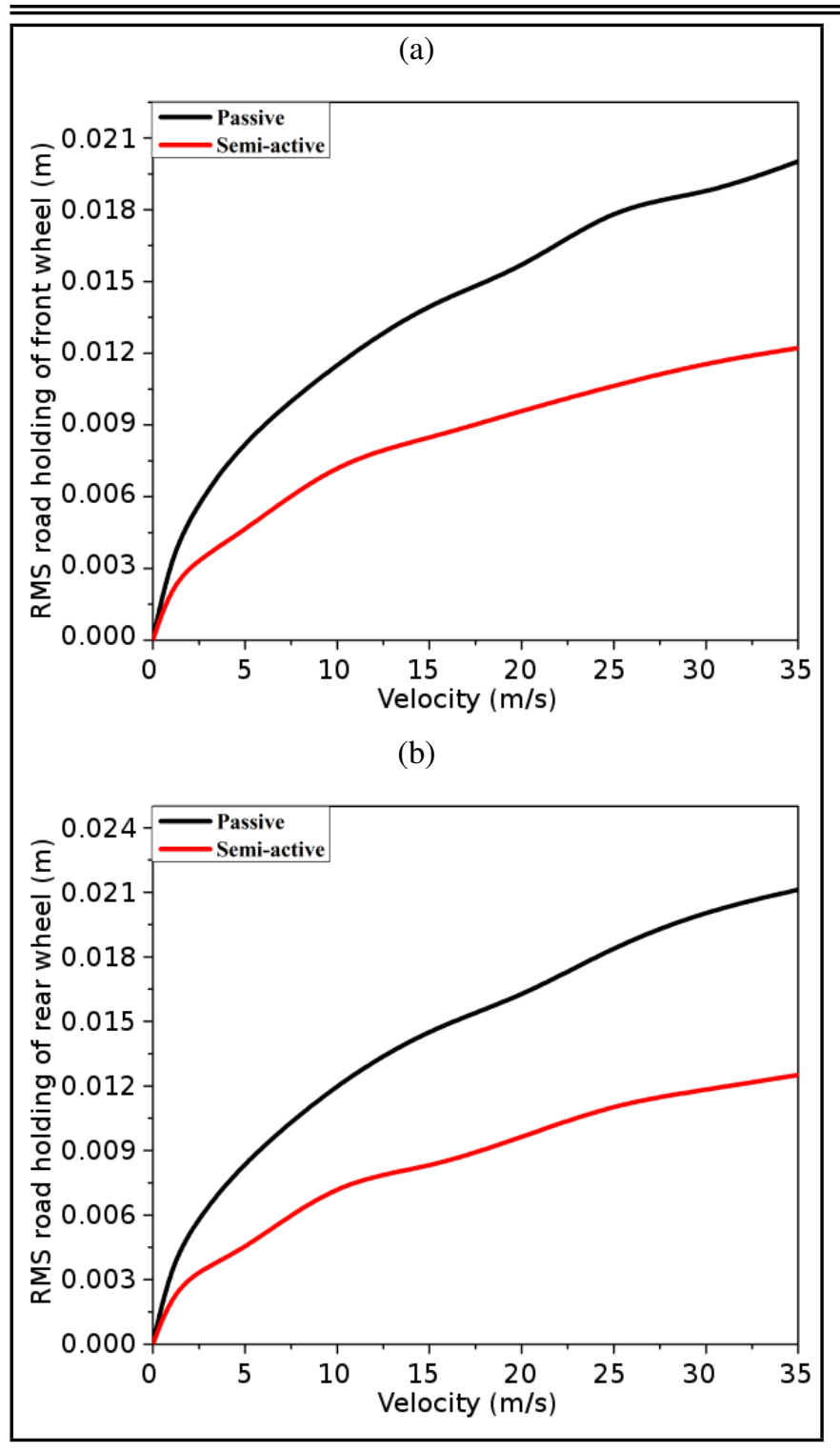

Figure 15. Road holding of the front and rear wheel.

fort enhancement, Engineering, 1(01), 23, (2009). https://dx.doi.org/10.4236/eng.2009.11004.

19 Rao, M., Ram, T. and Purushottam A., Analysis of passive and semi active controlled suspension systems for ride comfort in an omnibus passing over a speed bump, International Journal of Research and Reviews in Applied Sciences, 5(1), (2010).

20 Sireteanu, T. and Stoia, N., Damping optimization of passive and semi-active vehicle suspension by numerical simulation, Proceedings of the Romanian Academy, 4(2), 121127, (2002). https://dx.doi.org/10.1.1.510.1175

21 Turnip, A., Par, S. and Hong K. S., Sensitivity control of a MR-damper semi-active suspension, International Journal of Precision Engineering and Manufacturing, 11(2), 209218, (2010). https://dx.doi.org/10.1007/s12541-010-0024-1

22 Prabakar, R. S., Sujatha, C. and Narayanan, S., Optimal semi-active preview control response of a half-car vehicle model with magnetorheological damper, Journal of sound and vibration, 326(3), 400-420, (2009). https://dx.doi.org/10.1016/j.jsv.2009.05.032
23 Rossi, C., and Lucente, G., Hinf control of automotive semi-active suspensions, Proceedings of the 1st IFAC Symposium on Advances in Automotive Control ( $A A C)$, Salerno, Italy, (2004).

24 Eltantawie, M. A., Decentralized neuro-fuzzy control for half-car with semi-active suspension system, International Journal of Automotive Technology, 13(3), 423-431, (2012). https://dx.doi.org/10.1007/s12239-012-0039-y

25 Karkoub, M. A. and Zribi, M., Active/semi-active suspension control using magnetorheological actuators, International journal of systems science, 37(1), 35-44, (2006). https://dx.doi.org/10.1080/00207720500436344

26 Kasprzyk, J. and Krauze, P., Vibration control for a half-car model with adaptation of the magnetorheological damper model, Proceedings of the 6th International Conference on Modelling, Identification and Control (ICMIC), 243-248, (2014). https://dx.doi.org/10.1109/ICMIC.2014.7020759

27 Hrovat D., Applications of optimal control to advanced automotive suspension design, Journal of Dynamic Systems Measurement and Control, 115(2B), 328-342, (1993). https://dx.doi.org/10.1115/1.2899073

28 Talib, A., Hussin, M., Darns, M. and Zaurah, I., Self-tuning PID controller for active suspension system with hydraulic actuator, In IEEE Symposium on Computers and Informatics (ISCI), 86-91, (2013). https://dx.doi.org/10.1109/ISCI.2013.6612381

29 Kolekar, S., Kurahatti, R. V., Prashanth, P. K. Kamble, V. and Reddy, N., Preparation of a Silicon Oil based Magneto Rheological Fluid and an Experimental Study of its Rheological Properties using a Plate and Cone Type Rheometer, Institute of smart structures and system, 3, 23-26, (2014).

30 Sternberg, A., Zemp, R. and de la Llera, J. C., Multiphysics behavior of a magneto-rheological damper and experimental validation. Engineering Structures, 69, 194-205, (2014). https://dx.doi.org/10.1016/j.engstruct.2014.03.016

31 Sapinski, B. and Filus, J., Analysis of parametric models of MR linear damper, Journal of Theoretical and Applied Mechanics, 41(2), 215-240, (2003).

32 Deb, K. Multi-objective optimization using evolutionary algorithms, John Wiley and Sons (2001).

33 Shinozuka, M. and Jan, C. M., Digital simulation of random processes and itsapplications, Journal of sound and vibration, 25(1), 111-128, (1972). https://dx.doi.org/10.1016/0022-460X(72)90600-1

34 Patel, C. B., Gohil, P. P. and Borhade, B., Modelling and vibration analysis of a road profile measuring system, International Journal of Automotive and Mechanical Engineering (IJAME), 1, 13-28, (2010).

35 Gaur, S. and Sheilza J., Vibration Control of Bus Suspension System using PI and PID Controller, International Journal of Advances in Engineering Sciences, 3(3), 94-99, (2013). 